\title{
Ruin and Recreate Approach Applied to Multi-objective Optimization of HHC VRPTW in the Case of Medical Waste Collection
}

\author{
Mustapha Ahlaqqach*, Jamal Benhra, Salma Mouatassim and Safia Lamrani \\ LRI, OSIL Team, ENSEM, CELOG-ESITH, Casablanca, Morocco; ahlaqqach@gmail.com, jbenhra@hotmail.com, \\ mouatassimsalma@gmail.com, Moroccolamranisafia@yahoo.com
}

\begin{abstract}
Objectives: The management of Medical Waste in Morocco has always been the concern of the health department. Recently, the WHO classified the Medical Waste in Morocco as a time bomb, recommended involving of professionals interested in that management. Methods/Findings: Through this study we proposed a model of collectors' management, on behalf of clinics in case of Casablanca region. This model, as part of a heterogeneous fleet vehicle routing problem, aims at multiobjective optimization between the pillars of sustainable development. The complexity of the model is managed using a Ruin and Recreate heuristic. Application: Finally, the tuning of weighting parameters is being experimented to show how it will be possible to find a compromise between conflicting objectives in the case of Medical Waste logistics.
\end{abstract}

Keywords: Heterogeneous Fleet, Medical Waste, Multi-objective Optimization, Ruin and Recreate

\section{Introduction}

\subsection{Background}

According to the World Health Organization (WHO), the Medical Waste (MW), defined as those generated by medical care activities, includes infectious waste, pointed and sharp objects, chemicals, genotoxic waste and radioactive waste ${ }^{1}$. This kind of waste has an impact on the 3 pillars of Sustainable Development ${ }^{2}$ :

- Economical: The elimination of MW is more expensive than household waste.

- Social: Inadequate treatment of MW will negatively impact the safety and hygiene of patients, agents and the general public.

- Environmental: MWs present a very serious risk for the environment. Indeed, the uncontrolled emission of MW into the atmosphere causes the formation of toxic gases, food contamination and pollution of soil, surface water and groundwater.
Thus, the management of the MW becomes one of the pillars of the United Nations program for sustainable development. In ${ }^{3}$ the Moroccan context, government and operators are aware of this and steps have been taken to catch up on this issue. However, the field still reveals disparities between practices and what is promoted in the legislation. A report conducted by GIZ ${ }^{5}$ proposes the integration of professionals into MW's reverse logistics activity, given the industrial nature of this type of logistics. In order words, these professionals must work closely with public and health authorities to implement their business in harmony with the objectives of sustainable development.

\subsection{Medical Waste Collect and Vehicle Routing Problem}

The main objective of this work is to stick on to the aforementioned OMS suggestion and to show how it will be possible for professionals to cope with the pillars of sus-

*Author for correspondence 
tainable development in case of MW generated by clinics in the case of Casablanca's region. The problem therefore is to determine efficient routes for a fleet of vehicles transporting the MW from producers. These problems are known as Vehicle Routing Problem (VRP), where a fleet of vehicles starts from a central depot, serves a set of customer and come back to central depot. As our fleet is limited in capacity, the sum of MW collected by a single vehicle will not exceed its capacity. In this case we deal with Capacitated VRP (CVRP). As Casablanca is a region with very high traffic intensity during certain periods of the day, we have to set a Time Windows (TW) in which clinics will be served. Thus, we are in case of problems called CVRP with TW (CVRPTW). The work of ${ }^{6,7}$ are part of the recent work related to the VRPTW, they assumed that the deliveries to the customers can be done outside the TW (Soft TW), but on the other hand they induced penalties of delay in the objective function. However $\frac{8,9}{9}$ has adopted a strict system (Hard TW) wherein it is not allowed to deliver outside the TW. Another particularity is linked to our model, namely the nature of products collected from clinics which is classified, by the United Nations Economic Commission for Europe ${ }^{10}$, as Hazardous Materials (HazMat).

More than a few studies have considered the problem of waste collection. $\mathrm{In}^{11}$ used a special software program to solve the routing and scheduling problem and to reduce the cost arising from the daily transportation of the health-care wastes collected from the institutions. In $\frac{12}{}$ have presented a Pareto-based bi-objective optimization of hazardous materials vehicle routing and scheduling problem with TW and have showed its application to a realistic hazardous material logistics instance. $\operatorname{In} \frac{13}{3}$ have proposed a model of collectors' management and optimization of the incineration of hospital waste, on behalf of the University and Hospital Centers (CHU) and other medical centers. They optimized vehicle routing in upstream and downstream of the central warehouse. This study is followed by a particular case of MW $\frac{14}{4}$, in which the authors proposed a new design to collect the used healthcare textile. They used Genetic algorithm to optimize a Multi-objective (MO) model of VRPTW of Healthcare textile. In this paper, we will integrate the heterogeneity of the fleet. The risk factor is an unavoidable objective due to the nature of the MW, to which is added the routing cost. This MO character accentuates even more the complexity of our model qualified as the HazMat Heterogeneous Fleet CVRPTW (HHC VRPTW).

\subsection{Research Aims and Methodology}

Up to our knowledge, none of the existing studies have combined the MO with heterogeneous fleet in the case of MW. The present study fills a gap in the literature by combining several issues: Multi-objective model, heterogeneous fleet, single depot, strict TW, real case study using Geographic Information Systems (GIS) and MW (HazMat). The basic methodology used to seek trade-off between the main objectives related to the supply of MW included the following sections: The first section explains our proposal concerning the collect and centralization of MW collected at one Hub before incineration. Then, the mathematical model that governs the proposed model is presented in the second section. The following section shows Ruin and Recreate ( $\mathrm{R}$ and $\mathrm{R}$ ) heuristic. The fourth section presents the experimentation and results coming from the heuristic approach on the real traffic network of Casablanca region. Finally, we will confirm how it is possible to cope between the main objectives of the proposed model.

\section{Material and Methods}

\subsection{Proposed Structure}

It should be noted that the majority of clinics in Morocco are located in very sensitive areas, marked by fairly high traffic intensity, a massive population and a non-negligible accident rate. To these constraints, we add the fact that the collection of MW is often confused in a voluntary or involuntary way with that of household waste. In order

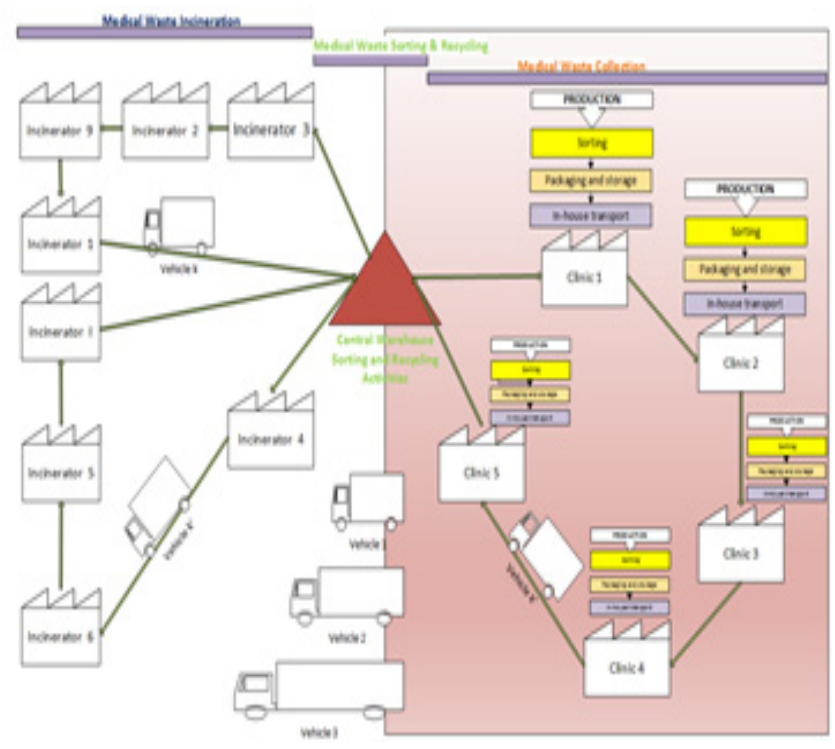

Figure 1. Proposed Medical Waste logistic structure. 
to limit the hemorrhage we will propose a new collection structure, shown in Figure 1 aimed at the interest of the professional and the community and suitable for sustainable development. The objective of this structure will be to ensure the collection of waste at the clinic level while optimizing the cost of collection and reducing the risk associated with the transport of MW, then a process of sorting and extracting of recyclable and valuable materials will be set off in a central warehouse. Finally, the unused wastes and hazardous materials will be serviced in incinerators. The time Table 1 shows the scheduling of the main activities in the case of our proposed structure. $\mathrm{I} n^{15}$ stated that environmental rules mandate daily treatment for $\mathrm{MW}$ if it is kept at room temperature, and weekly treatment if it is kept at temperature less than $5^{\circ} \mathrm{C}$. As this last condition is not available in Casablanca's clinics, waste collection and treatment is mandatory every two days. Therefore, we need to create a real-time decision-making system, where decision-making time is very important.

Table 1. Reverse logistic activities time table

\begin{tabular}{|l|l|l|l|}
\hline Time windows & $6 \mathrm{H} 11 \mathrm{H}$ & $11 \mathrm{H} 15 \mathrm{H}$ & $15 \mathrm{H} 19 \mathrm{H}$ \\
\hline $\begin{array}{l}\text { Main reverse } \\
\text { logistic } \\
\text { activities }\end{array}$ & MW collection & $\begin{array}{l}\text { MW } \\
\text { sorting and } \\
\text { recycling }\end{array}$ & $\begin{array}{l}\text { MW } \\
\text { incineration }\end{array}$ \\
\hline
\end{tabular}

\subsection{Model Formulation}

\subsubsection{Risk Calculation}

Several studies have sought to determine the best risk models, in our study we will focus on risk calculation presented by formula (1), because it fits our case of HazMat transportation and also for its simplicity.

$$
\mathrm{R}_{\mathrm{ij}}=\delta_{(\mathrm{i}, \mathrm{j})}{ }^{\star} \phi_{\mathrm{i}, \mathrm{j})}
$$

- $\delta_{(\mathrm{i}, \mathrm{j}) \mathrm{8}}$ Probability of a HazMat accident on the arc $(\mathrm{i}, \mathrm{j})$

- $\phi_{(\mathrm{i}, \mathrm{j})}$ Population exposed to contamination during the accident on the arc $(i, j)$

- To determine $\delta_{(\mathrm{i}, \mathrm{j}) \mathrm{8}}$ we will use Nicolet-Monnier and Gheorghe ${ }^{16}$ approach, who state that the formula of a HazMat accident is expressed by (2), where $\tau_{(\mathrm{i}, \mathrm{j})}$ and are respectively the HazMat accident rate and the length of the road $(i, j)$.

$$
\delta_{(\mathrm{i}, \mathrm{j})}=\tau_{(\mathrm{i}, \mathrm{j})} \mathrm{d}_{(\mathrm{i}, \mathrm{j})}
$$

- To assess $\phi_{(\mathrm{i}, \mathrm{j})}$ we will rely on the scheme presented in Figure 2 and commonly considered in the literature ${ }^{17,18}$ $\phi_{(i, j)}$ is obtained by a moving danger circle of radius $\lambda$ along the entire link ( $i, j)$. The value of $\lambda$, the HazMat spread radius, is depending upon the particular HazMat class under consideration (class 6.2 Infectious substances). The formula (3) is used for the computation of the accident consequences:

$$
\phi_{(i, j)}=\pi^{\star} \lambda^{2} \rho_{(\mathrm{i}, \mathrm{j})}
$$

- Where is is the average population density along arc $(i, j)$.

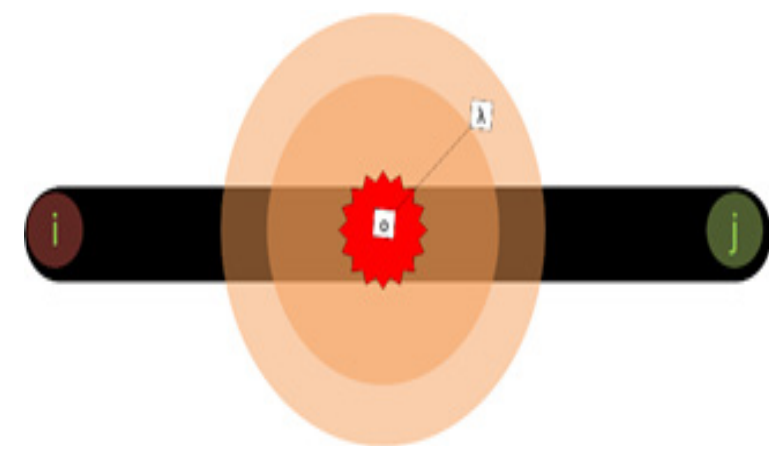

Figure 2. HazMat accident endangered area described by a circle of radius $\lambda$ in $\operatorname{arc}(i, j)$.

\subsubsection{Mathematical Formulation}

The parameters of our model are the following:

$\mathrm{Col}_{\mathrm{i}} \quad$ : MW generated by clinic $\mathrm{i}$; $\mathrm{i} \in \mathrm{I}$, where $\mathrm{I}$ is the set of clinics.

$b_{i}, e_{i} \quad$ : Start and End TW at the vertex i respectively; $\mathrm{i} \in\{0, . ., \mathrm{I}\}$.

Cvar $_{\mathrm{k}}$ : Transport variable cost, $\mathrm{k} \in \mathrm{K}$, where $\mathrm{K}$ is the set of heterogeneous vehicles.

Cfixe $_{\mathrm{k}}$ : Fixed cost if vehicle $\mathrm{k}$ is used,

$\mathrm{Ca}_{\mathrm{k}} \quad$ : Carrying capacity of the vehicle $\mathrm{k}, \mathrm{k} \in \mathrm{K}$

$\mathrm{s}_{\mathrm{i}} \quad$ : Service time at node $\mathrm{i}, \mathrm{i} \in\{0, \ldots, \mathrm{I}\}$.

$\mathrm{d}_{\mathrm{ij}}, \mathrm{t}_{\mathrm{ij}} \quad$ : Distance and travel time between $\mathrm{i}$ and $\mathrm{j}$ respectively, $\mathrm{i}, \mathrm{j} \in\{0, . ., \mathrm{I}\}$.

$\alpha, \beta \quad$ : Cost's and risk's Weighting respectively

The decision variables are:

$\mathrm{y}_{\mathrm{k}} \quad$ : A Binary Variable (BV) equal to 1 if vehicle $\mathrm{k}$ is used, 0 otherwise, $\forall \mathrm{k} \in \mathrm{K}$

$\mathrm{x}_{\mathrm{ijk}} \quad$ : A BV equal to 1 if $\operatorname{arc}(\mathrm{i}, \mathrm{j})$ is used by vehicle $\mathrm{k}, 0$ otherwise, $(i, j) \in N, k \in K$ 
$\mathrm{tw}_{\mathrm{i}}$ : A Continuous Variable (CV) which shows waiting time at node $\mathrm{i}, \forall \mathrm{i} \in \mathrm{I}$

$\mathrm{T}_{\mathrm{ik}} \quad$ : A CV which shows the departure time of request from node $i, \forall i \in I$

$\mathrm{Ta}_{\mathrm{k}}$ : A CV which shows the time at which vehicle $\mathrm{k}$ returns to its depot $\mathrm{k} \in \mathrm{K}$

$\mathrm{Td}_{\mathrm{k}}$ : A CV which shows the departure time of a vehicle $k$ from its depot node $k \in K$

qik : A quantity of Medical Waste served at clinic i by vehicle $\mathrm{k}$.

$\mathrm{Z}_{1} \quad$ : Total cost of routing (Variable cost + fixed cost of used vehicles).

$\mathrm{Z}_{2}$ : Total risk exposure associated with the transportation process.

The following equations manage our model:

Minimize $\alpha^{\star} Z_{1}+\beta^{\star} Z_{2}$

$Z_{1}=\sum_{k=1}^{K} y_{k}{ }^{\star} C f i x e_{k}+\sum_{i=0}^{n} \sum_{j=0}^{n} \sum_{k=1}^{K} x_{i j k}{ }^{\star} \operatorname{Cvar}_{k}{ }^{*} d_{i j}$

$\mathrm{Z}_{2}=\sum_{i=0}^{n} \sum_{j=0}^{n} \sum_{k=1}^{K} x_{i j k} R_{i j}$

$\sum_{i=0}^{n} \sum_{k=1}^{K} x_{i j k}=1 \quad j \in I$

$\sum_{j=0}^{n} \sum_{k=1}^{K} x_{i j k}=1 \quad i \in I$

$\sum_{i=0}^{n} x_{i p k}=\sum_{j=0}^{n} x_{p j k} \quad p \in I, k \in K$

$q_{j k}=\sum_{i=1}^{n} x_{i j k}{ }^{*} \operatorname{Col}_{j} j \in I, k \in K$

$\sum_{i=1}^{n} q_{i k} \leq c a_{k}^{*} y_{k} \quad k \in K$

$\sum_{j=1}^{n} x_{0 j k}=y_{k} k \in K$

$\sum_{i=1}^{n} x_{i 0 k}=y_{k} \quad k \in K$

$$
\begin{aligned}
& x_{i i k}=0 \quad i \in I, j \in J, k \in K \\
& T_{i k}+s_{i}+t_{i j}+t w_{j}-T_{j k} \leq\left(1-x_{i j k}\right)^{*} M \\
& i, j \in I, k \in K \\
& T_{i k}+s_{i}+t_{i 0}-T a_{k} \leq\left(1-x_{i 0 k}\right) * M \\
& i \in I, k \in K \\
& T_{d k}+t_{0 j}-T_{j k} \leq\left(1-x_{i 0 k}\right) \star M \\
& j \in I, k \in K \\
& b_{i}^{*} y_{k} \leq T_{i k} \leq e_{i}^{*} y_{k} i \in I, k \in K \\
& b_{0}^{*} y_{k} \leq T a_{k} \leq e_{0}^{*} y_{k} k \in K \\
& b_{0}^{*} y_{k} \leq T d_{k} \leq e_{0}^{*} y_{k} k \in K \\
& \alpha+\beta=1 \\
& x_{i j k}, y_{k} \in\{0,1\} t w_{i}, T_{i k}, q_{i k}, T a_{k}, T d_{k}, Z_{1} \text {, } \\
& Z_{2} \in \mathbb{R}^{+} i, j \in\{0 . . n\}, k \in K
\end{aligned}
$$

Equation (4) expresses the MO function to optimize, taking into account the total cost factor and the total risk of the transportation process. Equations (5) and (6) are the components of the objective function. The objective functions are subjected to constraints (7) to (22). Equations (7) and (8) enforce each clinic to be serviced once by a unique truck and a unique arc. Equation (9), (12) and (13) guarantee flow conservation. Equations (10) and (11) ensure the collect quantity in the clinic and the respect of trucks capacity respectively. The loop is avoided by the Equation (14), while Equations (15)(20) compute the time variables and ensure that the TW are respected, also they avoid sub-tours. The sum of the weights, equal to 1, is expressed in Equation (21) and Equation (22) defines the variables.

\subsection{Ruin and Recreate Heuristic}

As mentioned before, the MO character of the case studied accentuates even more the complexity of HTWVRP. Thus, the exact approach is not efficient to resolve the mathematical formulation shown above. In our instance, we have a network of 36 clinics and a single depot, each clinic presents a departure and arrival vertex. Besides, our fleet is composed of 20 vehicles and then we will 
have 60153 constraints and 28942 decision variables. Based on the vast studies, a ruin and Recreate ( $\mathrm{R}$ and $\mathrm{R}$ ) Heuristic is proposed to cope with large-scale instances. This Heuristic was proposed by $\frac{19}{}$ as a new method for more complex optimization problems, particularly with complex objectives. It is a large neighborhood search that combines elements of simulated annealing and thresholdaccepting algorithms. The basic idea of $\mathrm{R}$ and $\mathrm{R}$ is to obtain new optimization solutions by a considerable obstruction of an existing solution and a following rebuilding procedure. Consequently, $\mathrm{R}$ and $\mathrm{R}$ has two stages:

\subsubsection{Ruin}

Tree methods, named Radial ruin, Random ruin and Sequence ruin, are proposed to remove several customers from the solution. All the methods are based on an arbitrarily chosen base customer.

\subsubsection{Recreate}

Customers removing from routes during the ruin stage of the algorithm are now inserted using 'best insertion'. Iteratively, the customer is chosen at random from the set of removing customers. The 'best insertion' position for this customer is then calculated and the customer is inserted into this position. The insertion is performed only if the resulting solution is feasible. Otherwise, an additional vehicle will be inserted into the system.

In our case, we choose this heuristic because it produces a stronger results and it is best suited for complex problems that have many constraints and a discontinue solution space ${ }^{20}$.

The steps of the algorithm proposed in our case are presented as follows:

Step 1: Start with an initial configuration;

Step 2: Ruin mode: we will choose a mixture of Radial ruin and Random ruin;

Step 3: Choose a number $\mathrm{A}<=[\mathrm{F} \cdot \mathrm{N}]$ of clinics to be removed, where $\mathrm{F}$ is a fraction between 0 and 1 and $\mathrm{N}$ all clinics;

Step 4 and 5: Ruin followed by Recreate;

Step 6: Decide if you accept the new solution according to a decision rule. In our case we will use Simulated Annealing Threshold Accepting: $\mathrm{T}=\mathrm{T}_{0}$. Exp $(-\ln 2 ; \mathrm{x} / \alpha)$, where $\mathrm{T}_{0}$ is the initial threshold, $\alpha$ the half-life and $x$ the schedule variable. If you accept, proceed with the step 2, using the new solution, else restart with step 2 using the current solution.

\section{Case Study}

\subsection{Parameters of Computational Study}

Set of clinics and vehicles: The clinics shown in the Figures 3 and 4 are 36 clinics disseminated in the whole region of Casablanca. Thanks to Google map we get addresses and coordinates of each clinic and the distance and travel time matrices. Analysis of the historical data from each clinic revealed the stability of the quantities of Medical Waste generated daily by each clinic. Consequently, based on the number of bed per clinic and the fact that the average waste generation rate in Moroccan health instance is $3 \mathrm{~kg} / \mathrm{bed} /$ day, where $20 \%$ of are MW, we estimated the MW generated by each clinic. The distance between vehicle parking and waste storage in each clinic help us to estimate the unloading time. We have adopted a geographical breakdown based on the intensity of traffic. Consequently, areas with high traffic density should be served early before $8 \mathrm{am}$. The size of the fleet is 20 vehicles and it is composed of 6 categories of vehicles with different capacities. The fixed costs vary from one category to another with a gain in economies of scale in the case of large capacity vehicles. The average variable cost of the costs communicated by the operators in the waste collection is of the order of 2 (Moroccan Dirhams) MAD per $\mathrm{Km}$.

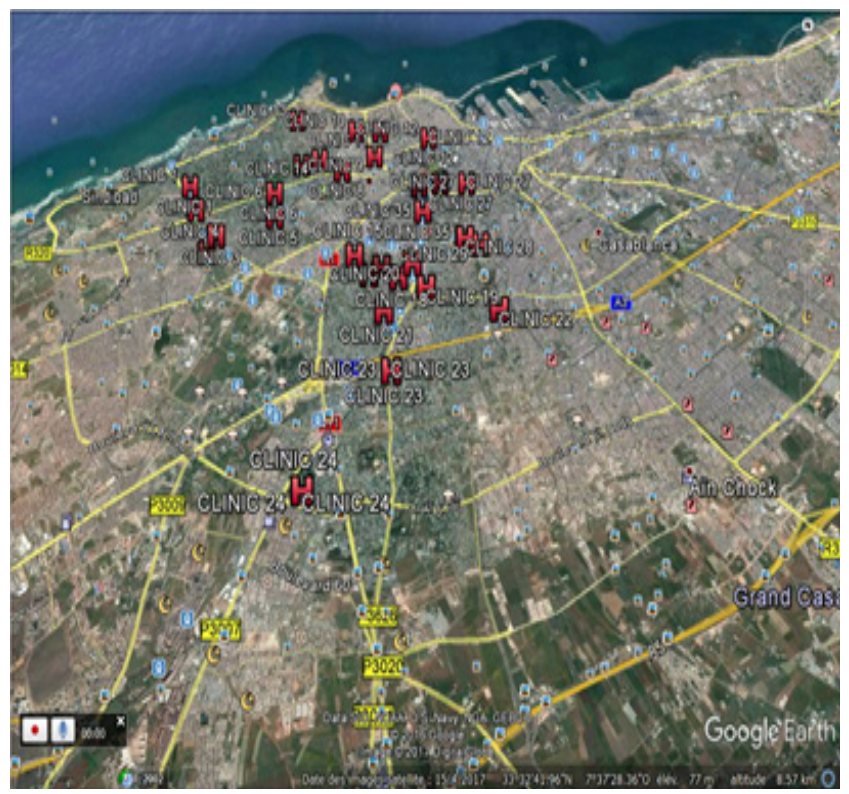

Figure 3. Clinics dissemination in the region of Casablanca. 


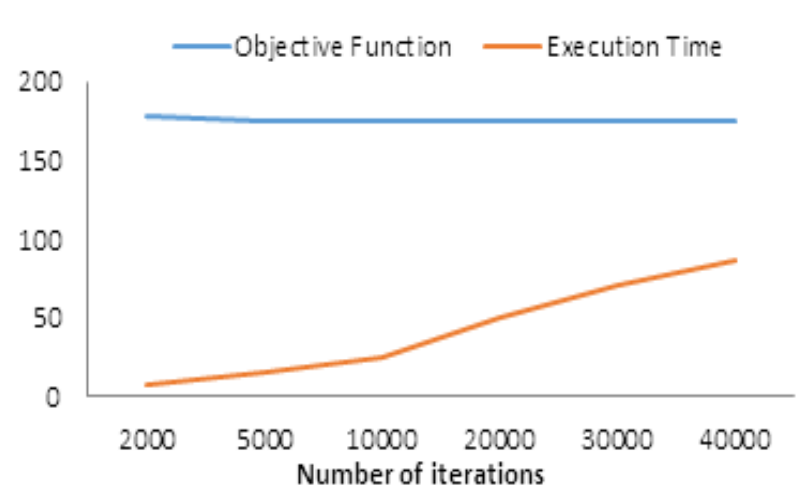

Figure 4. The objective function and the execution time according to number of iterations $(\alpha=0.005)$.

\subsubsection{Accident Rates}

Based on the report of $\frac{21}{2}$, the number of HazMat accident in Morocco recorded a maximum of 21 HazMat accidents in 2001. We experienced difficulties to have statistics concerning the MW accident rate. Consequently, we have worked with the data used by $\frac{18}{}$, who estimated that the class 6 is nearby $5.2 \%$ of HazMat accident. Then, the number of $\mathrm{MW}$ accident is near to 1.38 accidents/ year. The estimated fleet size used in Medical Waste is about 200 vehicles and each vehicle browses $11520 \mathrm{Km} /$ year. Thus the HazMat accident rate is $6 \times 10^{-7}$ accident/ Truck.Km.year. Based on the Equation (3) we evaluated the probability of HazMat accident matrix.

\subsubsection{Population Exposure}

The Equation (4) needs the radius $\lambda$ and the average population density along arc $(\mathrm{i}, \mathrm{j}): \rho_{(\mathrm{i}, \mathrm{j})}$. The radius of a danger circle was adopted from the report 1996 HazMat Routing Guide of $\frac{22}{}$, which recommended a value of $\lambda=5$ miles for HazMat of class 6 . The statistics coming from the general census of population in $\mathrm{Morocco}^{2 \underline{23}}$ helps us to find the average population density along $\operatorname{arc}(i, j)$. Based on radius $\lambda=5$ miles and the average population density along each road we got the risk matrix.

\subsection{3 $R$ and $R$ Parameters}

To solve this problem, we will use the same implementation as ${ }^{\frac{19}{}}$. The initial threshold To is set to be half of the standard deviation of the objective function during a random walk. The half-life $\alpha$ is set to 0.1 and the schedule variable $\mathrm{x}$ will be increased from 0 to 1 during the optimization run. We will apply a mixture of Radial ruin and
Random ruin, using $\mathrm{F}=0.3$ and $\mathrm{F}=0.5$, respectively. To define the parameter number of iterations, we varied this parameter according to the values 2000, 5000, 10000, 20000, 30000 and 40000. We find that, for several value of $\alpha$, starting from 5000 iterations, the objective function does not improve, while the execution time grows in a spectacular way. Thus, one will opt for 5000 iterations.

\section{Results}

The case studied was coded in Java and implemented on an Intel CORE Duo CPU with a $2.53 \mathrm{Ghz}$ processor and 3 GB of RAM installed memory under Windows 7.

The result of the test is presented in Table 2 and the routes are mapped in Figure 5. The experimentation validated the robustness of the model. Indeed, the results obtained from the experimentation respect all the constraints linked to the model. All the clinics are serviced by vehicles and the model gives an objective function of the order of 223.18. Each bloc on the table correspond to a routing proposed by $\mathrm{R}$ and $\mathrm{R}$ heuristic, for example the first bloc correspond to the first routing, where the vehicle chosen is vehicle $(\mathrm{k}=15)$, Whose capacity of 20 tons can contain the 20 tons of MW collected in the clinics that constitute this routing namely: depot-clinic5- clinic4clinic 34- clinic 33-depot. The start service corresponds to the time in which the vehicle arrives to serve a clinic. All the start service respects the time window. The $\mathrm{R}$ and $\mathrm{R}$ Heuristic proposed 9 routings. The assignment of vehicles is adequate for each routing. Indeed, the fill rate is about $99 \%$. We recall that we didn't get global optimum when we launched a model on IBM ILOG CPLEX Optimization Studio 12.2 due to the complexity of the model. The best results obtained by CPLEX, before stopping because of the memory problem, were achieved after 800 seconds. After this limit the CPLEX gave the result presented in the Table 3. On one hand, the objective function given by CPLEX is 308.56 , which present a gap of $30 \%$ to the relaxed solution. On the other hand the objective function resulting from $\mathrm{R}$ and $\mathrm{R}$ Heuristic is of the order of 223.18 , so a difference of $27 \%$ compared to the CPLEX solution and a gap of $3 \%$ to relaxed solution. Beside this, the resolution time of the $\mathrm{R}$ and $\mathrm{R}$ heuristic is much more interesting. Indeed, the time is 12 seconds for the $\mathrm{R}$ and $\mathrm{R}$ heuristic whereas it was 775 seconds for the CPLEX resolution. This speed in terms of resolution is of paramount importance in the life of companies today where we are 


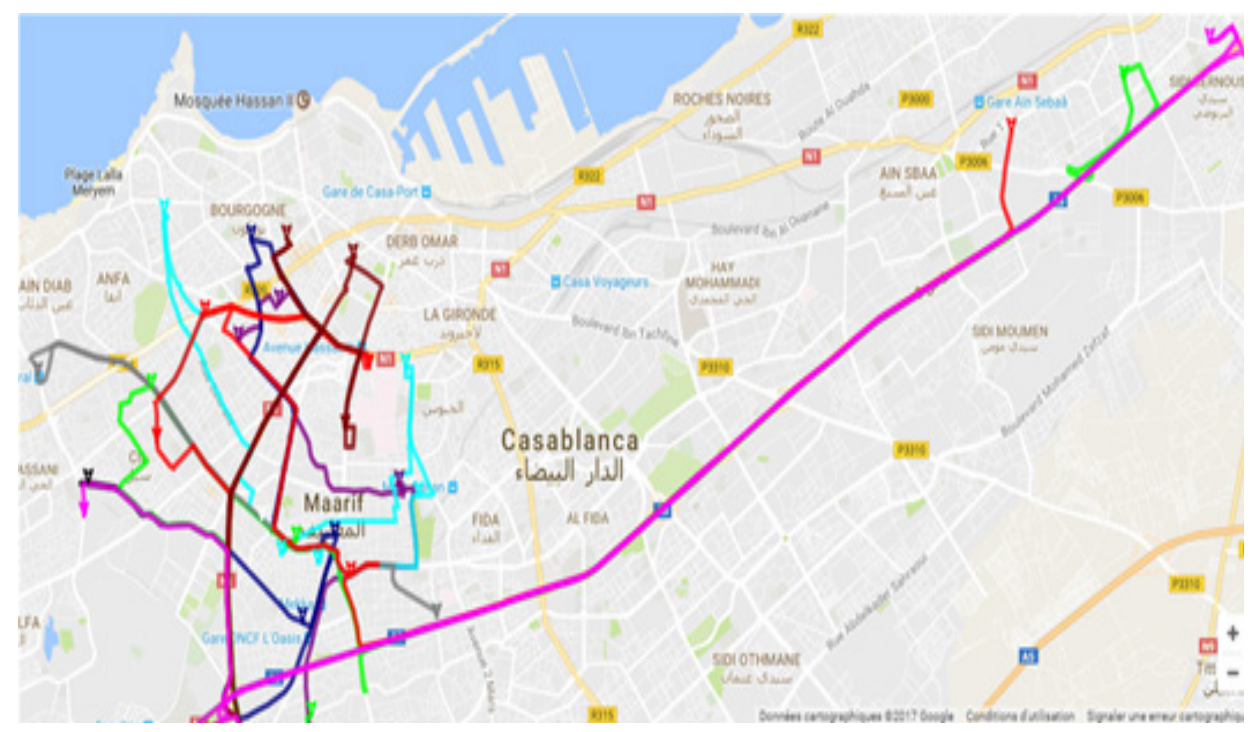

Figure 5. Collection routing proposed by $\mathrm{R}$ and $\mathrm{R}$ heuristic.

Table 2. Results of the $\mathrm{R}$ and $\mathrm{R}$ validation test

\begin{tabular}{|c|c|c|c|c|c|c|c|c|c|c|}
\hline \multirow{4}{*}{$\begin{array}{l}\text { Routing } \\
1 \text { vehicle } \\
\mathbf{k}=15 \\
\text { Capacity } \\
=20\end{array}$} & Routing & $\mathbf{0}$ & 5 & 4 & 34 & 33 & $\mathbf{0}$ & & & \multirow{3}{*}{$\begin{array}{l}\text { Total } \\
\text { Collected } \\
\text { (tons) }\end{array}$} \\
\hline & Start service & 0 & 30 & 38 & 53 & 59 & 0 & & & \\
\hline & Time Windows & $0-300$ & $20-120$ & $20-120$ & $20-300$ & $20-300$ & $0-300$ & & & \\
\hline & Quantity collected & 0 & 3.5 & 6 & 6 & 4.5 & 0 & & & 20 \\
\hline \multirow{4}{*}{$\begin{array}{l}\text { Routing } \\
2 \text { vehicle } \\
k=18 \\
\text { Capacity } \\
=30\end{array}$} & Routing & 0 & 24 & 29 & 27 & 25 & 12 & 18 & $\mathbf{0}$ & \multirow{3}{*}{$\begin{array}{l}\text { Total } \\
\text { Collected } \\
\text { (tons) }\end{array}$} \\
\hline & Start service & 0 & 21 & 37 & 47 & 55 & 67 & 90 & 0 & \\
\hline & Time Windows & $0-300$ & $20-240$ & $20-180$ & $0-180$ & $0-240$ & $20-120$ & $0-300$ & $0-300$ & \\
\hline & Quantity collected & 0 & 6 & 8.5 & 4 & 3.5 & 3.5 & 4 & 0 & 29.5 \\
\hline \multirow{4}{*}{$\begin{array}{l}\text { Routing } \\
3 \text { vehicle } \\
\mathbf{k}=20 \\
\text { Capacity } \\
=30\end{array}$} & Routing & $\mathbf{0}$ & 15 & 8 & 11 & 9 & 14 & 3 & 0 & \multirow{3}{*}{$\begin{array}{l}\text { Total } \\
\text { Collected } \\
\text { (tons) }\end{array}$} \\
\hline & Start service & 0 & 26 & 38 & 50 & 59 & 70 & 85 & 120 & \\
\hline & Time Windows & $0-300$ & $20-180$ & $20-120$ & $20-120$ & $20-120$ & $20-120$ & $20-120$ & $0-300$ & \\
\hline & Quantity collected & 0 & 3.5 & 4 & 2.5 & 8.5 & 6 & 4.5 & 1 & 30 \\
\hline \multirow{4}{*}{$\begin{array}{l}\text { Routing } \\
3 \text { vehicle } \\
\mathbf{k}=10 \\
\text { Capacity } \\
=16\end{array}$} & Routing & $\mathbf{0}$ & 20 & 19 & $\mathbf{0}$ & & & & & \multirow{3}{*}{$\begin{array}{l}\text { Total } \\
\text { Collected } \\
\text { (tons) }\end{array}$} \\
\hline & Start service & 0 & 27 & 34 & 62 & & & & & \\
\hline & Time Windows & $0-300$ & $0-180$ & $20-180$ & $0-300$ & & & & & \\
\hline & Quantity collected & 0 & 7.5 & 8.5 & 0 & & & & & 16 \\
\hline \multirow{4}{*}{$\begin{array}{l}\text { Routing } \\
5 \text { vehicle } \\
\mathbf{k}=17 \\
\text { Capacity } \\
=20\end{array}$} & Routing & $\mathbf{0}$ & 21 & 22 & 30 & 31 & 32 & $\mathbf{0}$ & & \multirow{3}{*}{$\begin{array}{l}\text { Total } \\
\text { Collected } \\
\text { (tons) }\end{array}$} \\
\hline & Start service & 0 & 23 & 33 & 53 & 65 & 76 & 119 & & \\
\hline & Time Windows & $0-300$ & $0-180$ & $20-180$ & $20-240$ & $20-240$ & $20-240$ & $0-300$ & & \\
\hline & Quantity collected & 0 & 2.5 & 3.5 & 7.5 & 2.5 & 3.5 & 0 & & 19.5 \\
\hline
\end{tabular}




\begin{tabular}{|c|c|c|c|c|c|c|c|c|c|c|}
\hline \multirow{4}{*}{$\begin{array}{l}\text { Routing } \\
6 \text { vehicle } \\
k=1 \\
\text { Capacity } \\
=5\end{array}$} & Routing & $\mathbf{0}$ & 23 & $\mathbf{0}$ & & & & & & \multirow{3}{*}{$\begin{array}{l}\text { Total } \\
\text { Collected } \\
\text { (tons) }\end{array}$} \\
\hline & Start service & 0 & 22 & 48 & & & & & & \\
\hline & Time Windows & $0-300$ & $20-180$ & $0-300$ & & & & & & \\
\hline & Quantity collected & 0 & 4.5 & 0 & & & & & & 4.5 \\
\hline \multirow{4}{*}{$\begin{array}{l}\text { Routing } \\
7 \text { vehicle } \\
\mathbf{k}=19 \\
\text { Capacity } \\
=30\end{array}$} & Routing & $\mathbf{0}$ & 2 & 1 & 7 & 13 & 10 & 26 & 0 & \multirow{3}{*}{$\begin{array}{l}\text { Total } \\
\text { Collected } \\
\text { (tons) }\end{array}$} \\
\hline & Start service & 0 & 31 & 40 & 46 & 51 & 58 & 70 & 106 & \\
\hline & Time Windows & $0-300$ & $20-120$ & $20-180$ & $20-120$ & $20-120$ & $20-120$ & $20-180$ & $0-300$ & \\
\hline & Quantity collected & 0 & 3.5 & 2.5 & 4 & 4.5 & 7.5 & 8 & 0 & 30 \\
\hline \multirow{4}{*}{$\begin{array}{l}\text { Routing } \\
8 \text { vehicle } \\
k=16 \\
\text { Capacity } \\
=20\end{array}$} & Routing & 0 & 17 & 16 & 6 & 0 & & & & \multirow{3}{*}{$\begin{array}{l}\text { Total } \\
\text { Collected } \\
\text { (tons) }\end{array}$} \\
\hline & Start service & 0 & 26 & 30 & 42 & 78 & & & & \\
\hline & Time Windows & $0-300$ & $20-180$ & $20-180$ & $20-120$ & $0-300$ & & & & \\
\hline & Quantity collected & 0 & 4 & 8 & 8 & 0 & & & & 20 \\
\hline \multirow{4}{*}{$\begin{array}{l}\text { Routing } \\
9 \text { vehicle } \\
\mathrm{k}=11 \\
\text { Capacity } \\
=16\end{array}$} & Routing & 0 & 36 & 28 & 35 & 0 & & & & \multirow{3}{*}{$\begin{array}{l}\text { Total } \\
\text { Collected } \\
\text { (tons) }\end{array}$} \\
\hline & Start service & 0 & 29 & 33 & 40 & 75 & & & & \\
\hline & Time Windows & $0-300$ & $20-180$ & $20-180$ & $20-180$ & $0-300$ & & & & \\
\hline & Quantity collected & 0 & 8 & 4 & 3.5 & 0 & & & & 15.5 \\
\hline
\end{tabular}

Table 3. Comparison between R and R Heuristic and CPLEX results (large instance)

\begin{tabular}{|l|l|l|}
\hline & R\&R & CPLEX \\
\hline Transport Cost & 15873 & 16384 \\
\hline Risk Assessment & 96.97 & 178.92 \\
\hline Total & 223.18 & 308.56064 \\
\hline Best Node (Relaxed solution) & \multicolumn{2}{|l|}{216.30} \\
\hline GAP to Relaxed Solution & $3 \%$ & $30 \%$ \\
\hline Vehicle Utilization & 9 & 10 \\
\hline Vehicle Fill rate & $99 \%$ & $91.67 \%$ \\
\hline Execution Time (seconds) & 12 & $\begin{array}{l}775.2 \text { (Run out after } 800 \\
\text { seconds) }\end{array}$ \\
\hline
\end{tabular}

not ready to wait for hours to make operational decisions, hence the interest of the heuristic approach. These results above justify the acceptability of a proposed algorithm's performance.

\subsection{Experimentation of the Weighting Parameters}

To perform this experiment, we varied the weighting of $\alpha$ to see the risk impact on the components of the objective function and the execution time. The variation of $\alpha$ value gave us an approximation to the Pareto-optimal solution set. The reinforcement of the risk coefficient, starting from $\beta>=0.991$, leads to an increase in routing costs. Indeed, the integration of the risk factor makes the paths at very high risks rejected; therefore the model will choose longer and costly paths. As the fleet is heterogeneous the model may choose costly trucks as it focuses on risk optimization. This double disturbance will negatively affect the cost aspect of the objective function. In contrast, the reinforcement of the risk coefficient, starting from $\beta>=0.991$, leads to a better control of the risk during the execution of the routing. The tuning of the parameters $\alpha$ and $\beta$, made it possible to locate the sensitivity zone of the objective function. Figures 6 and 7 show the Pareto optimal solutions for 5000 and 30000 iterations respectively. Both cases illustrate the same con- 


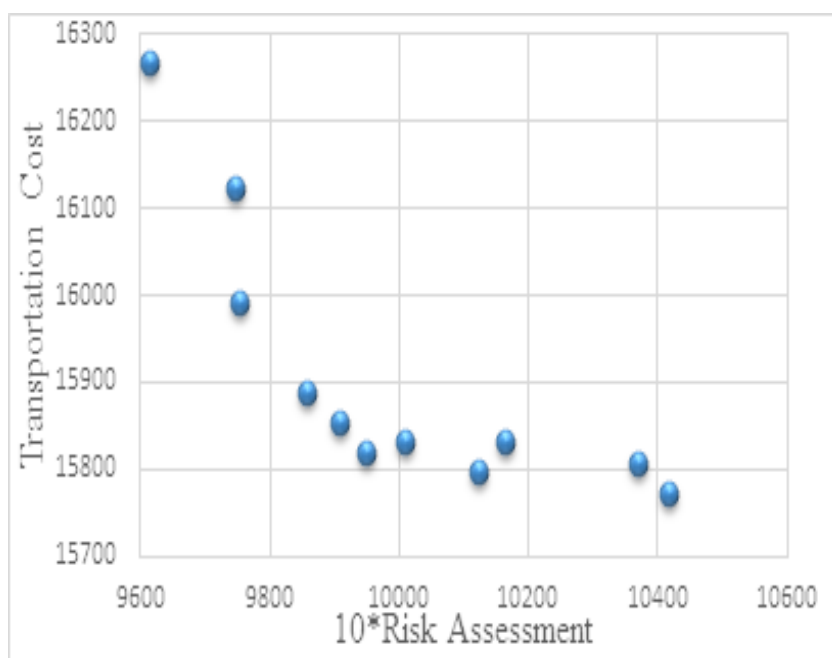

Figure 6. Trade-off curve cost and risk (5000 iterations).

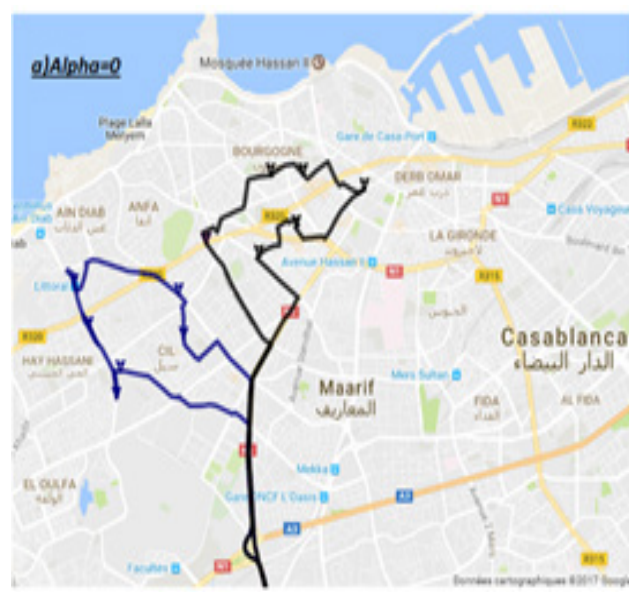

(a)

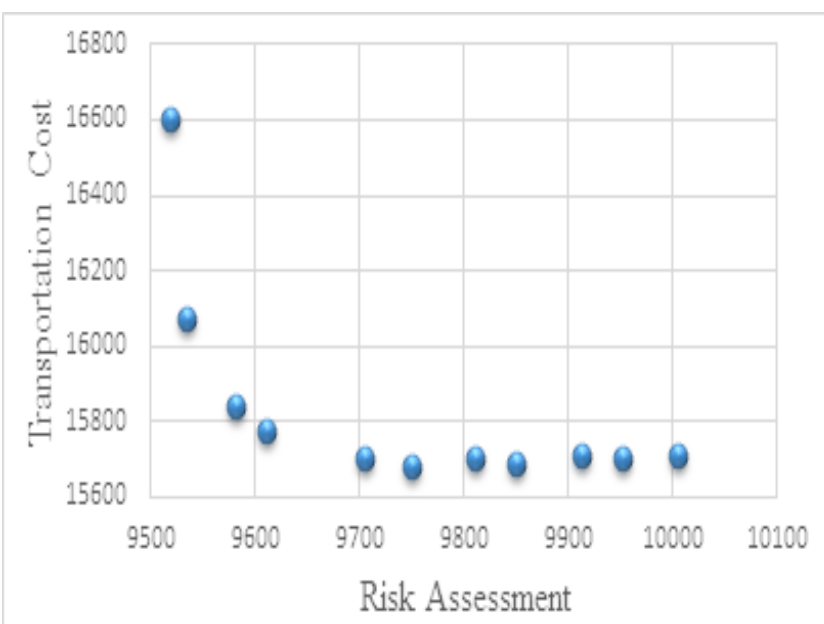

Figure 7. Trade-off curve cost and risk (30000 iterations).

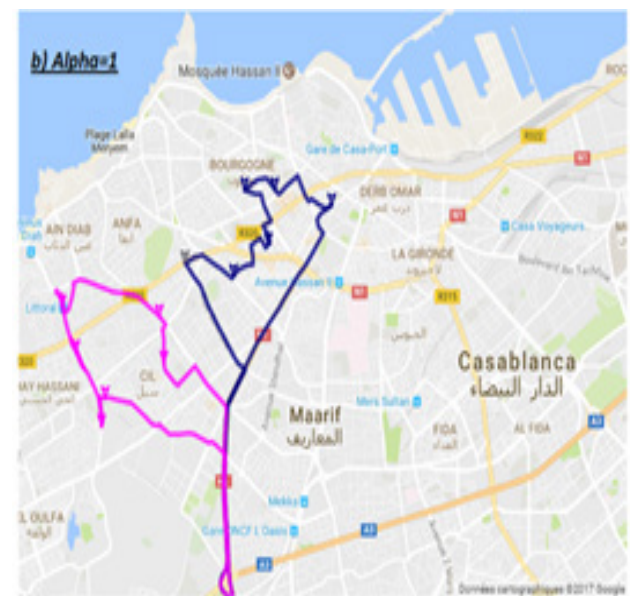

(b)

Figure 6. (a) Minimum risk solution and (b) minimum cost solution

flict of objectives as explained above. Based on the Pareto optimal solutions, one can find the best trade-off between these conflict objectives.

To better visualize the routes resulting from this heuristic according to the value of $\alpha$, we present the routing scheme on a map for the case of small instance (12 Clinics). Figure 8.a shows the routing exposed to the minimum of the risk and Figure 8.b gives the routing generating the minimum cost. The reader could notice easily that the solution with the minimum risk ( $\alpha=0$, Black line) tends to be longer and consequently more expensive compared to the solution with the minimum cost ( $\alpha=1$, Blue line). As mentioned above, the risky paths are rejected for the benefit of longer paths. It will be interesting to challenge our results with other studies, in order to emphasize the approach chosen. However, in our knowledge, it is the first time that the subject of HHCVRPTW was conducted in the case of Medical Waste collection in Casablanca region. That's why we didn't experiment any benchmark in this research, to catch up with this gap we will launch a similar study where we will challenge the $\mathrm{R}$ and $\mathrm{R}$ heuristic with a meta-heuristic.

\section{Conclusion}

This research sheds new light on the case of MW collect in the region of Casablanca, by proposing a $\mathrm{MO}$ mathematical model with a heuristic resolution of a very complicated case of VRP. Our aim was to find a solution to a problem that humanity is experiencing. To this end, we have 
taken into consideration several realistic characteristics of the problem in order to make the model close to reality. The hazardous nature of the waste has led us to integrate the risk associated with the transport of these materials. The heterogeneity of the fleet and the choice of vehicles as required are the main distinctions of this model in a framework of optimization of the HHCV RPTW.

The complexity of the case leads us to use RR heuristic, which gave a good result in a reasonable time for the real instance. Then we vary the weighting of cost and risk in order to seek for potential trade-off between cost and risk. The latter tuning allowed us to conclude that thanks to this model, we can seek a compromise between the different stakeholders in the project of Medical Waste collect. RR heuristic performance is highly acceptable in both small and large-scale cases.

The reader should bear in mind that the study is based on assumptions, such as data related to the routes, which is supposed to be static. Except in reality, roads are subject to traffic that varies over time. This variation is due to several factors such as peak hours, hazards due to accidents, specific events, unexpected disturbances (breakdown of traffic control lights, unplanned work, etc.). Thus, for a better contribution in the framework of our scientific research, there is some guidance for future research. We will create an interface between the model and a geographical map, taking into consideration the dynamics of the information concerning the itineraries. This information will enable us to generate in real time changes in the routing of vehicles. Due to practical constraints, this paper did not experiment other meta-heuristic to challenge $\mathrm{R}$ and $\mathrm{R}$ heuristic, which is based on local search. For this reason, the future contribution will focus on a meta-heuristic to challenge the results coming from $\mathrm{R}$ and $\mathrm{R}$ heuristic in the case of $\mathrm{MW}$ collection in the region of Casablanca.

\section{References}

1. OMS, Organisation mondiale de la Sante.| Les dechets lies aux soins de sante. 2018. http://www.who.int/mediacentre/ factsheets/fs $253 / \mathrm{fr} /$

2. Les dechets et le developement durable au CHUHopitaux de Rouen. 2011. https://hermes.chu-rouen.fr/ cclin/documents/documents_coclinnor/21_juin_2011/ Presentation_Cocclinor_21_juin_2011.pdf

3. United Nations Development Programme. 2019. http:// www.undp.org/content/undp/en/home/ourwork/sustain- able-development/natural-capital-and-the-environment/ chemicals-and-waste-management.html

4. Mbarki A, Kabbachi B, Ezaidi A, Benssaou M. Medical Waste management: A case study of the Souss-Massa-Draa Region, Morocco. Journal of Environmental Protection. 2013; 4(2):914-9. https://doi.org/10.4236/jep.2013.49105

5. Country report on the solid waste management in Morocco. 2010. https://www.resource-recovery.net/en/system/files/ countryreportmorocco-en-mai2011.pdf

6. Tas D, Dellaert N, Van Woensel T, De Kok T. Vehicle routing problem with stochastic travel times including soft time windows and service costs. Computer Operation Research. 2013; 40(1):214-24. https://doi.org/10.1016/j. cor.2012.06.008

7. Figliozzi MA. An iterative route construction and improvement algorithm for the VRP with soft time windows. Transportation Research Part C: Emerging Technologies. 2010; 18(5):668-79. https://doi.org/10.1016/j. trc.2009.08.005

8. Agra A, Christiansen M, Figueiredo R, Hvattum LM, Poss M, Requejo C. The robust vehicle routing problem with time windows. Computer Operation Research. 2013; 40(3):856-66. https://doi.org/10.1016/j.cor.2012.10.002

9. Vidal T, Crainic TG, Gendreau M, Prins C. A hybrid genetic algorithm with adaptive diversity management for a large class of vehicle routing problems with time-windows. Computer Operation Research. 2013; 40(1):475-89. https://doi.org/10.1016/j.cor.2012.07.018

10. United Nations Economic Commission for Europe. ADR European Agreement Concerning the International Carriage of Dangerous Goods by Road. New York and Geneva. 2014, 1.

11. Alago AZ, Nay Kocasoy G. Improvement and modification of the routing system for the health-care waste collection and transportation in Istanbul. Waste Management. 2008; 28(8):1461-71. PMid: 17949966. https://doi.org/10.1016/j. wasman.2007.08.024

12. Pradhananga R, Taniguchi E, Yamada T, Qureshi AG. Bi-objective decision support system for routing and scheduling of hazardous materials. Socio-economic Planning Sciences. 2014; 48(2):135-48. https://doi.org/10.1016/j. seps.2014.02.003

13. Ahlaqqach M, Benhra J, Mouatassim S. Optimization of routing for the collection and delivery of Medical Waste passing through a common warehouse. Logistique Management. 2007; 25(1):25-33. https://doi.org/10.1080/1 2507970.2017.1310601

14. Ahlaqqach M, Benhra J, Mouatassim S, Lamrani S. Smart city through the control of the healthcare textiles transport. SSRN Electronic Journal. 2018. 
15. Shih LH, Chang HC. A routing and scheduling system for infectious waste collection. Environment Model Assess. 2001;6(4):261-9.https://doi.org/10.1023/A:1013342102025

16. Nicolet-Monnier M, Adrian G. Quantitative risk assessment of topics in safety, risk, reliability and quality. Dordrecht, Netherland. 1996.

17. Batta R, Chiu SS. Optimal obnoxious paths on a network: Transportation of hazardous materials on JSTOR. Operations Research. 1988; 36(1):84-92. https://doi. org/10.1287/opre.36.1.84

18. Erkut E, Tjandra SA, Verter V. Hazardous materials transportation. Handbooks in Operations Research and Management Science. 2007; 43:239-621. https://doi. org/10.1016/S0927-0507(06)14009-8
19. Schrimpf G, Schneider J, Stamm-wilbrandt H, Dueck G. Record breaking optimization results using the ruin and recreate principle. Journal of Computer Physics. 2000; 171:139-71. https://doi.org/10.1006/jcph.1999.6413

20. Walker J. Design of vehicle routing problem domains for a hyper-heuristic framework. University of Nottingham. 2015.

21. EL Metoui M. Projet de loi n³0-05 relatif au transport par route des marchandises danger uses. 2006. p. 1-46.

22. US Department of transportation (US DOT). Highway Routing of Hazardous Materials Guidelines for Applying Criteria. Washington, DC. 1996.

23. Recensement general de la population et de l'ahbitat 2014 Note de presentation des premiers resultants Region du grand Casablanca. 2018. https://www.hcp.ma/downloads/ RGPH-2014_t17441.html 